\title{
Manejos do solo associados a telas de sombreamento no cultivo da cebolinha no verão
}

\author{
Andréia CS Hirata ${ }^{1}$; Edson K Hirata ${ }^{2}$; Patrícia A Monquero ${ }^{3}$ \\ ${ }^{1}$ Agência Paulista de Tecnologia dos Agronegócios (APTA), Presidente Prudente-SP, Brasil; andreiacs@apta.sp.gov.br; ${ }^{2}$ Universidade \\ do Oeste Paulista (UNOESTE), Álvares Machado-SP, Brasil; edson.pesquisa@yahoo.com.br; ${ }^{3}$ Universidade Federal de São Carlos \\ (UFSCAR), Araras-SP, Brasil; pamonque@cca.ufscar.br
}

\section{RESUMO}

Telas de sombreamento são amplamente utilizadas no sistema produtivo das hortaliças folhosas, todavia são desconhecidos os efeitos dessa tecnologia na cultura da cebolinha cultivada no verão. O objetivo desse trabalho foi avaliar a redução do preparo de solo, associado a telas de sombreamento, em cultivos sucessivos da cebolinha no verão. $\mathrm{O}$ experimento foi implantado no esquema de parcelas subdivididas com manejos do solo nas parcelas $(1=$ grade aradora + grade niveladora + enxada rotativa encanteiradora e $2=$ grade aradora + grade niveladora) e manejos do ambiente nas subparcelas $(1=$ tela preta $35 \% ; 2=$ tela preta $50 \% ; 3=$ tela prata $35 \%$; $4=$ tela prata $50 \%$ e $5=$ pleno sol). As respostas da cebolinha ao uso de telas de sombreamento em relação ao pleno sol diferiram com as condições meteorológicas no verão. Em situação de altas temperaturas do ar e menor precipitação pluvial, a produtividade da cebolinha sob as telas foi equivalente ao pleno sol, todavia com incremento na precipitação e redução das temperaturas, o cultivo a pleno sol foi mais produtivo. Plantas cultivadas sob telas de sombreamento apresentaram incremento em altura. Efeito positivo das telas foi verificado na manutenção da umidade do solo, especialmente na superfície. O preparo do solo com grade aradora + grade niveladora apresentou maior retenção de água em todas as profundidades avaliadas, em relação ao manejo com grade aradora + grade niveladora + enxada rotativa encanteiradora, todavia houve decréscimo de produtividade de $21,7 \%$ (primeiro cultivo) e $14,9 \%$ (segundo cultivo) sem preparo de canteiro.

Palavras-chave: Allium fistulosum, sombrite, preparo de solo.

\section{ABSTRACT}

Soil managements associated with shading screens in bunching onion during summer season

Polyethylene screens have been widely used in leafy vegetable production system, but there is no research of this technology in bunching onion growing during the summer season. This study aimed to evaluate the association of reduced soil disturbance with shading screens in bunching onion successive cropping in the summer. The experiment was established in split-plot scheme, comprising two soil management strategies $(1=$ disc harrow + leveling disc harrow + rotary tilling and $2=$ disc harrow + leveling disc harrow) in the plots and environmental management strategies $(1=$ black screen $35 \%$; $2=$ black screen $50 \% ; 3=$ silver screen $35 \%$; $4=$ silver screen $50 \%$ and $5=$ full sun) in the subplots. The responses of bunching onion cropping in shading screens or full sunlight differed with meteorological conditions in the summer. Plants growing in high temperatures and less rainfall presented similar yield regardless the use of polyethylene screens or cultivation under full sun conditions. In the opposite situation, bunching onion growing under full sun is more productive. Bunching onion height increased in plants growing under polyethylene screens. There was positive effect of shading screens in maintaining soil moisture, especially on the surface. Disc harrow + leveling disc harrow presented higher water retention at all soil depths evaluated. However, the yield decreased $21.7 \%$ (first crop) and $14.9 \%$ (second crop) in relation to disc harrow + leveling disc harrow + rotary tilling.

Keywords: Allium fistulosum, shading-net, soil tillage.

(Recebido para publicação em 21 de junho de 2015; aceito em 22 de setembro de 2016) (Received on June 21, 2015; accepted on September 22, 2016)

$\mathrm{D}$ entre os fatores climáticos, a luz e a temperatura são os que mais limitam o cultivo de hortaliças (Puiatti \& Finger, 2005). Apesar de suportar frios prolongados e de existir cultivares que resistam bem ao calor, com poucas restrições para o seu plantio em qualquer época do ano, a cultura da cebolinha é adaptada a condições de temperaturas amenas (Filgueira, 2000).

A busca por um melhor ambiente para o cultivo de hortaliças tem sido o foco principal de muitas pesquisas. Atualmente, são muitas as opções disponíveis no mercado com relação a tipos de estruturas e de materiais que podem ser usados para modificar o ambiente $\mathrm{e}$ adequá-lo às necessidades das culturas (Feltrim et al., 2006).

O cultivo de hortaliças sob telas de sombreamento tem sido estudado para folhosas como alface (Queiroga et al.,
2001; Bezerra Neto et al., 2005; Queiroz et al., 2014) e rúcula (Costa et al., 2011; Hirata, 2014), todavia, há carência de trabalhos com o cultivo de cebolinha sob telas de sombreamento, especialmente no verão.

Outro aspecto relevante no sistema produtivo de hortaliças é o predomínio de elevado revolvimento do solo onde a prática de levantamento de canteiros é comum (Oliveira et al., 2006). A enxada 
rotativa utilizada para essa operação é um equipamento com significativa capacidade desagregante. A pulverização do solo resultante dessa operação o expõe à erosão, uma vez que os agregados grandes conferem ao solo maior resistência contra a erosão (Carvalho Filho et al., 2007).

Assim, o desenvolvimento de sistemas de produção, que assegurem o equilíbrio do ambiente e seus recursos, soluciona o desafio de gerar soluções e adotar práticas culturais conservacionistas (Tavella et al., 2010), visando mitigar os processos erosivos causados pelo excessivo revolvimento de solo na época chuvosa (Melo et al., 2010).

O objetivo deste trabalho foi avaliar manejos do solo associados a telas de sombreamento em cultivos sucessivos de cebolinha no verão.

\section{MATERIAL E MÉTODOS}

O experimento foi instalado na Agência Paulista de Tecnologia dos Agronegócios (APTA), no Polo Regional da Alta Sorocabana, em Presidente Prudente-SP $\left(22^{\circ} 07^{\prime} 21 S^{\prime \prime}, 51^{\circ} 23^{\prime} 17^{\prime \prime} \mathrm{O}\right.$, altitude $460 \mathrm{~m}$ ); de acordo com a classificação de Köppen, o clima é classificado como Aw, tropical chuvoso com inverno seco e mês mais frio com temperatura média superior a $18^{\circ} \mathrm{C} . \mathrm{O}$ mês mais seco tem precipitação inferior a $60 \mathrm{~mm}$ (CEPAGRI, 2015).

$\mathrm{O}$ ensaio foi realizado em solo classificado como Argissolo Vermelho-Amarelo, classificação textural areia-franca, com $6,4 \%$ de argila, $10,3 \%$ de silte e $83,3 \%$ de areia total, com predominância de areia fina e muito fina. As características químicas foram $\mathrm{pH}$ em $\mathrm{CaCl}_{2}$ de 6,1; matéria orgânica de $17 \mathrm{~g} /$ $\mathrm{dm}^{3}$; saturação de bases de $68 \%$; teores de $\mathrm{P}, \mathrm{Zn}, \mathrm{Fe}, \mathrm{Mn}, \mathrm{Cu}, \mathrm{B}$ de 100,0; 2,3; 18,$0 ; 7,7 ; 2,1 ; 0,18 \mathrm{mg} / \mathrm{dm}^{3}$ e de $\mathrm{K}, \mathrm{Ca}$, $\mathrm{Mg}, \mathrm{H}+\mathrm{Al}$ de 3,$0 ; 50,0 ; 15,0$ e 11,0 mmolc $/ \mathrm{dm}^{3}$, respectivamente. A análise química foi realizada de acordo com o método proposto por Raij et al. (2001).

Os tratamentos foram dispostos em esquema de parcelas subdivididas, sendo as parcelas principais compostas pelos manejos do solo (1= grade aradora + grade niveladora + enxada rotativa encanteiradora ou $2=$ grade aradora + grade niveladora) e nas subparcelas avaliados manejos do ambiente ( $1=$ tela preta $35 \% ; 2=$ tela preta $50 \% ; 3=$ tela prata $35 \% ; 4=$ tela prata $50 \%$ e $5=$ pleno sol). O delineamento experimental foi de blocos ao acaso, com quatro repetições.

A área experimental foi cultivada com milheto (setembro), sendo roçado e incorporado 60 dias antes da instalação do experimento. O preparo do solo de toda a área experimental no plantio consistiu de uma aração (grade aradora) e uma gradagem (grade niveladora), todavia, nos tratamentos com preparo de canteiros, os mesmos foram levantados por meio de uma enxada rotativa encanteiradora, com $130 \mathrm{~cm}$ de largura e 30 $\mathrm{cm}$ de altura. A adubação e correção do solo foi baseada no Boletim 100 (Raij et al., 1997), sendo utilizado termofosfato e a formulação NPK 20-00-20 no plantio e cloreto de potássio, uréia e sulfato de amônio na adubação de cobertura. Foi utilizada no experimento a cultivar de cebolinha Tokyo Kuro, sendo as mudas produzidas em bandejas de polipropileno com capacidade para 288 mudas. As mudas foram transplantadas em $03 / 01 / 2015$, no espaçamento de $30 \times 15$ $\mathrm{cm}$. No segundo plantio as mudas foram transplantadas em 20/02/2015.

As plantas foram irrigadas quando necessário, por meio de um sistema de gotejamento, com três mangueiras por canteiro, sendo os furos gotejadores espaçados em $30 \mathrm{~cm}$, sendo que cada furo emitia $1,2 \mathrm{~L} / \mathrm{h}$ de água.

A unidade experimental foi constituída por $2 \mathrm{~m}$ de comprimento e $1,2 \mathrm{~m}$ de largura $\left(2,4 \mathrm{~m}^{2}\right)$, com quatro linhas de cebolinha. Em cada linha foram transplantadas 13 mudas (cada muda com 14 plantas). A área para avaliação foi constituída pelas duas linhas centrais, desprezando-se duas plantas das extremidades das linhas. As parcelas foram mantidas capinadas por meio de capina manual.

As telas foram instaladas a $1 \mathrm{~m}$ de altura do solo, individualmente nas parcelas, sendo fechados os quatro lados das parcelas com as respectivas telas. Arames fixados em palanques foram esticados para inserir as telas e utilizados grampos para prendê-las no solo. Os tratamentos foram dispostos no campo com a distância necessária para evitar sombreamento entre as parcelas.

Nos meses de janeiro, fevereiro, março e abril de 2015 , a temperatura máxima média mensal do ar foi de 34,5 ; 32,$1 ; 31,1$ e $30,9^{\circ} \mathrm{C}$ e a da temperatura mínima média mensal foi de 21,6; 20,8; 19,7 e $18,3^{\circ} \mathrm{C}$, respectivamente (CIIAGRO, 2015).

Nos dois cultivos da cebolinha, a umidade do solo foi avaliada na semana anterior à colheita. A amostragem foi realizada na parte central dos canteiros. As amostras de solo foram acondicionadas em latas de alumínio e levadas ao laboratório para pesagem. Em seguida, as latas foram colocadas em estufa de circulação forçada de ar à temperatura de $105^{\circ} \mathrm{C}$, até atingirem massa constante, segundo método da Embrapa (1997).

A altura do dossel foi avaliada nos dois cultivos, semanalmente até a colheita. No primeiro e segundo cultivo as plantas foram colhidas com 42 e 49 dias após o transplante, respectivamente. $\mathrm{Na}$ colheita foram coletadas plantas inteiras sendo levadas ao laboratório, lavadas e as raízes cortadas rente aos bulbos. A massa da matéria fresca foi obtida das touceiras individualmente. Também foram determinados o diâmetro da touceira, diâmetro médio por planta em cada touceira, número final de plantas por touceira. A massa da matéria fresca das plantas e o teor de massa seca foi obtido por meio de estufa de circulação forçada de ar, onde as plantas permaneceram até obtenção de peso constante.

Os dados foram submetidos à análise de variância por meio do programa estatístico Assistat (Silva, 2008), sendo as médias comparadas pelo teste de Tukey, a $5 \%$ de probabilidade, para os dados qualitativos, sendo estabelecidas curvas de regressão para os dados quantitativos.

\section{RESULTADOS E DISCUSSÃO}

Não houve interação entre os manejos do solo e do ambiente em ambos os cultivos da cebolinha para as variáveis avaliadas. Para o número de plantas por cova não houve efeito dos tratamentos em ambos os cultivos. Para as demais variáveis houve diferença significativa entre as telas de sombreamento e/ou en- 
tre os manejos do solo nos dois cultivos (Tabelas 1 e 2).

No primeiro cultivo, as massas de matérias frescas das plantas cultivadas sob telas de sombreamento e a pleno sol não diferiram entre si. A massa de matéria seca foi numericamente superior no tratamento a pleno sol, diferindo apenas da tela prata $50 \%$, e esta não diferiu das demais telas. O teor de massa seca, foi superior no cultivo a pleno sol, sugerindo um possível maior teor de água nas plantas cultivadas sob telas, tornando-as mais tenras. De acordo com Larcher (2006), plantas que crescem sob forte radiação desenvolvem folhas espessas e a luminosidade do habitat pode promover alterações tanto na morfologia quanto na fisiologia das mesmas.

No segundo cultivo, a massa de matéria fresca, assim como da matéria seca e do teor de matéria seca, das plantas cultivadas sob as telas de sombreamento foi inferior ao das plantas cultivadas a pleno sol. De modo geral, o uso de telas com maior porcentagem de sombreamento promoveu em magnitude menor massa da matéria fresca. Nem todas as espécies apresentam resposta positiva ao sombreamento, sendo que algumas apresentam redução de produtividade com o sombreamento proporcionado pelas telas (Chagas et al., 2010; Costa et al., 2014), o que é reflexo da adaptabilidade de cada espécie à restrição de luz.

As condições meteorológicas de ambos os períodos de cultivo dentro do verão também explicam o desempenho produtivo da cultura. As temperaturas do ar, avaliadas em estação meteorológica, foram muito altas no primeiro cultivo, sendo que as máximas absolutas variaram de 32,5 a $39,2^{\circ} \mathrm{C}$ e a precipitação acumulada foi de $208,7 \mathrm{~mm}$, o que igualou os resultados das telas e do tratamento a pleno sol, uma vez que as telas têm função de proteção contra o excesso de radiação solar e chuvas fortes. O decréscimo das temperaturas no segundo cultivo resultou em menor estresse para a cultura, sendo verificadas temperaturas máximas absolutas de 29,5 a $34,5^{\circ} \mathrm{C}$ e precipitação acumulada de $378,1 \mathrm{~mm}$ (CIIAGRO, 2015). A maior ocorrência de chuvas neste período resultou também em maior quantidade de dias nublados o que, associado ao

Tabela 1. Produtividade e componentes de produção da cebolinha sob diferentes manejos do solo e do ambiente, no verão (primeiro cultivo) \{bunching onion yield and production components under different soil and environment management, in the summer (first cropping)\}. Presidente Prudente, APTA, 2015.

\begin{tabular}{|c|c|c|c|c|c|c|}
\hline \multirow{2}{*}{ Telas } & MF & MS & \multirow{2}{*}{$\begin{array}{l}\text { TMS } \\
(\%)\end{array}$} & DT & DP & \multirow{2}{*}{ NP } \\
\hline & \multicolumn{2}{|c|}{ (g/cova) } & & \multicolumn{2}{|c|}{ (cm) } & \\
\hline Preta $35 \%$ & $105,6 \mathrm{a}$ & $6,9 \mathrm{ab}$ & $6,6 \mathrm{~b}$ & $3,2 \mathrm{a}$ & $0,56 a$ & $13,3 \mathrm{a}$ \\
\hline Preta $50 \%$ & $108,1 \mathrm{a}$ & $6,8 \mathrm{ab}$ & $6,4 \mathrm{bc}$ & $3,3 \mathrm{a}$ & $0,55 \mathrm{a}$ & $13,4 \mathrm{a}$ \\
\hline Prata $35 \%$ & $117,2 \mathrm{a}$ & $7,8 \mathrm{ab}$ & $6,7 b$ & $3,4 \mathrm{a}$ & $0,57 \mathrm{a}$ & $13,2 \mathrm{a}$ \\
\hline Prata $50 \%$ & $108,1 \mathrm{a}$ & $6,7 \mathrm{~b}$ & $6,3 \mathrm{c}$ & $3,3 \mathrm{a}$ & $0,55 \mathrm{a}$ & $13,5 \mathrm{a}$ \\
\hline Sem tela & $108,2 \mathrm{a}$ & $7,9 \mathrm{a}$ & $7,4 \mathrm{a}$ & $3,5 \mathrm{a}$ & $0,58 \mathrm{a}$ & $13,6 \mathrm{a}$ \\
\hline $\mathrm{CV}(\%)$ & 11,3 & 7,1 & 3,5 & 7,1 & 7,3 & 7,4 \\
\hline \multicolumn{7}{|l|}{ Manejos } \\
\hline Com canteiro & $122,7 \mathrm{a}$ & $7,9 \mathrm{a}$ & $6,5 \mathrm{a}$ & $3,5 \mathrm{a}$ & $0,58 \mathrm{a}$ & $13,1 \mathrm{a}$ \\
\hline Sem canteiro & $96,1 b$ & $6,6 \mathrm{~b}$ & $6,9 \mathrm{a}$ & $3,2 \mathrm{a}$ & $0,54 \mathrm{a}$ & $13,7 \mathrm{a}$ \\
\hline $\mathrm{CV}(\%)$ & 22,0 & 14,5 & 8,2 & 10,4 & 9,4 & 17,8 \\
\hline
\end{tabular}

Médias seguidas de letras iguais nas colunas não diferem entre si pelo teste de Tukey (5\%) \{means followed by the same letter in the columns do not differ by Tukey test $(5 \%)\} . \mathrm{MF}=$ massa da matéria fresca (fresh mass); TMS= teor de matéria seca (dry mass content); MS= massa da matéria seca (dry mass); DT= diâmetro da touceira (diameter of the bunch); $\mathrm{DP}=$ média do diâmetro individual das plantas (individual plants mean diameter); $\mathrm{NP}=$ número de plantas por cova (number of plants per hole).

Tabela 2. Produtividade e componentes de produção da cebolinha, sob diferentes manejos do solo e do ambiente, no verão (segundo cultivo) \{bunching onion yield and production components under different soil and environment management, in the summer (second cropping)\}. Presidente Prudente, APTA, 2015.

\begin{tabular}{lccccccc}
\hline \multirow{2}{*}{ Telas } & \multicolumn{2}{c}{ MF } & MS & TMS & \multicolumn{1}{c}{ DT } & DP & \multirow{2}{*}{ NP } \\
\cline { 2 - 3 } \cline { 6 - 7 } & \multicolumn{2}{c}{$(\mathbf{g} / \mathbf{c o v a})$} & & \multicolumn{2}{c}{$\mathbf{( \mathbf { c m } )}$} & & \\
\hline Preta 35\% & $115,9 \mathrm{bc}$ & $8,7 \mathrm{bc}$ & $7,5 \mathrm{~b}$ & $3,3 \mathrm{bc}$ & $0,55 \mathrm{bc}$ & $13,5 \mathrm{a}$ \\
Preta 50\% & $99,0 \mathrm{c}$ & $7,2 \mathrm{c}$ & $7,3 \mathrm{~b}$ & $3,1 \mathrm{c}$ & $0,50 \mathrm{c}$ & $14,0 \mathrm{a}$ \\
Prata 35\% & $126,0 \mathrm{~b}$ & $9,5 \mathrm{~b}$ & $7,6 \mathrm{~b}$ & $3,5 \mathrm{~b}$ & $0,57 \mathrm{~b}$ & $14,0 \mathrm{a}$ \\
Prata 50\% & $108,3 \mathrm{bc}$ & $7,9 \mathrm{bc}$ & $7,3 \mathrm{~b}$ & $3,4 \mathrm{bc}$ & $0,55 \mathrm{bc}$ & $13,0 \mathrm{a}$ \\
Sem tela & $163,3 \mathrm{a}$ & $13,2 \mathrm{a}$ & $8,1 \mathrm{a}$ & $3,9 \mathrm{a}$ & $0,71 \mathrm{a}$ & $12,9 \mathrm{a}$ \\
\hline CV $(\%)$ & 3,7 & 12,2 & 3,4 & 5,6 & 6,4 & 8,5 \\
\hline Manejos & & & & & & \\
\hline Com canteiro & $132,3 \mathrm{a}$ & $9,9 \mathrm{a}$ & $7,4 \mathrm{~b}$ & $3,5 \mathrm{a}$ & $0,57 \mathrm{a}$ & $13,7 \mathrm{a}$ \\
Sem canteiro & $112,6 \mathrm{~b}$ & $8,7 \mathrm{~b}$ & $7,7 \mathrm{a}$ & $3,4 \mathrm{a}$ & $0,58 \mathrm{a}$ & $13,3 \mathrm{a}$ \\
\hline CV (\%) & 14,2 & 4,9 & 1,5 & 10,2 & 9,4 & 15,8 \\
\hline
\end{tabular}

Médias seguidas de letras iguais nas colunas não diferem entre si pelo teste de Tukey, a $5 \%$ de probabilidade Means followed by the same letter in the columns do not differ by Tukey test $\} ; \mathrm{MF}=$ massa da matéria fresca (fresh mass); TMS = teor de matéria seca (dry mass content); $\mathrm{MS}=$ massa da matéria seca (dry mass); $\mathrm{DT}=$ diâmetro da touceira (diameter of the bunch); $\mathrm{DP}=$ média do diâmetro individual das plantas (mean diameter of individual plants); $\mathrm{NP}=$ número de plantas por cova (number of plants per hole).

sombreamento proporcionado pelas telas, resultou em efeito adverso na produtividade comparado ao pleno sol. Trabalhos têm mostrado o impacto das condições meteorológicas no desempenho das culturas (Caliman et al., 2005; Steinmetz et al., 2013). Wolff \& Coltman (1990) também verificaram que as respostas das plantas são distintas de acordo com a época de cultivo. De acordo com esses autores, a cebolinha não apresentou incremento em produtividade com sombreamento de 30 a $70 \%$, sendo que a resposta foi até negativa de acordo com a estação do ano (primavera ou outono). 


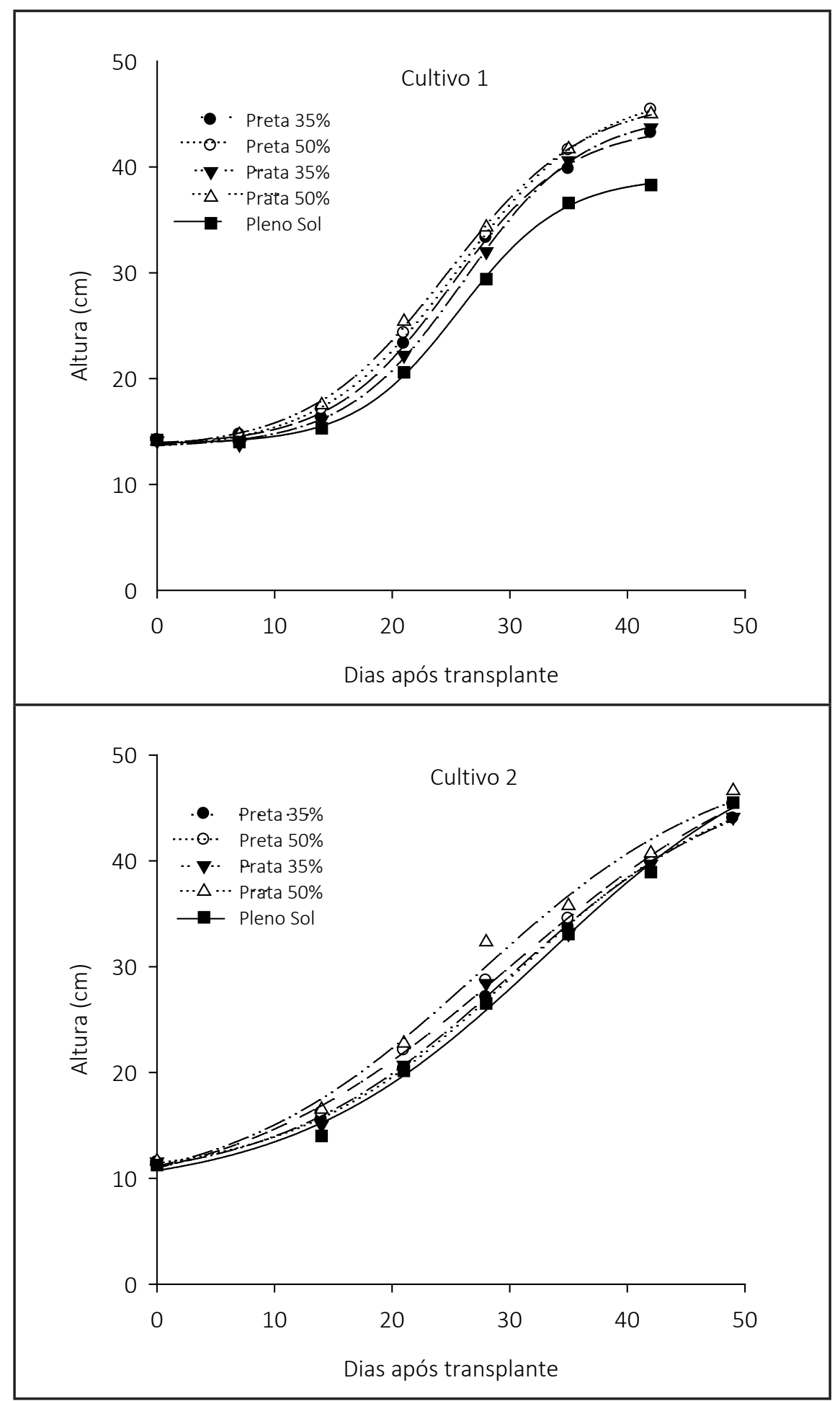

Figura 1. Altura da cebolinha em cultivos sucessivos sob telas de sombreamento, no verão (bunching onion height in consecutive cropping under shading screen, in the summer). Presidente Prudente, APTA, 2015.

cultivo 1: $\mathrm{Y}_{\text {preta } 35 \%}=13,7515+30,1626 /(1+\exp [-(\mathrm{x}-25,0341) / 5,0364)] \mathrm{R}^{2}=0,99 ; \mathrm{Y}_{\text {preta }}$ ${ }_{50 \%}=13,2302+33,9618 /(1+\exp [-(\mathrm{x}-25,5228) / 5,7958)] \mathrm{R}^{2}=0,99 ; \mathrm{Y}_{\text {prata } 35 \%}=13,5422+$ $31,5308 /(1+\exp [-(\mathrm{x}-26,1116) / 5,0578)] \mathrm{R}^{2}=0,99 ; \mathrm{Y}_{\text {prata } 50 \%}=13,3168+33,2381 /(1+\exp$ $[-(\mathrm{x}-24,6584) / 5,8450)] \mathrm{R}^{2}=0,99 ; \mathrm{Y}_{\text {pleno sol }}=13,8485+25,2127 /(1+\exp [-(\mathrm{x}-25,6999) / 4,4217)]$ $\mathrm{R}^{2}=0,99$; cultivo 2: $\mathrm{Y}_{\text {preta } 35 \%}=9,9618+38,6967 /(1+\exp [-(\mathrm{x}-30,3934) / 9,3902)] \mathrm{R}^{2}=0,99$; $\mathrm{Y}_{\text {preta } 50 \%}=7,6817+45,0984 /(1+\exp [-(\mathrm{x}-30,2677) / 11,9323)] \mathrm{R}^{2}=0,99 ; \mathrm{Y}_{\text {prata } 35 \%}=9,3484$ $+39,5357 /(1+\exp [-(\mathrm{x}-29,9834) / 9,8863)] \mathrm{R}^{2}=0,99 ; \mathrm{Y}_{\text {prata } 50 \%}=8,1792+42,1979 /(1+\exp$ $[-(\mathrm{x}-27,2421) / 10,5348)] \mathrm{R}^{2}=0,99 ; \mathrm{Y}_{\text {pleno sol }}=8,7614+44,5292 /(1+\exp [-(\mathrm{x}-33,0468) / 10,7652)]$ $\left.\mathrm{R}^{2}=0,99\right)$.
O diâmetro das touceiras e de plantas individuais não diferiu entre os tratamentos no primeiro cultivo, todavia, o tratamento a pleno sol apresentou resultados superiores no segundo cultivo, sendo verificadas plantas com talos mais grossos.

Quanto ao efeito do preparo do solo, as massas de matéria fresca e seca da cebolinha foram maiores no manejo com grade aradora + grade niveladora + enxada rotativa encanteiradora em relação à operação com grade aradora + grade niveladora. $\mathrm{O}$ plantio sem preparo de canteiro apresentou redução de 21,7 e $14,9 \%$ na massa da matéria fresca no primeiro e segundo cultivo, respectivamente. Considerando que os experimentos foram realizados em época de cultivo adversa (verão), os resultados da redução na produtividade, com o menor revolvimento do solo, podem ser avaliados como promissores, considerando ainda uma redução de custo, visto que neste tratamento houve uma operação a menos de preparo de solo.

A altura das plantas diferiu entre as telas de sombreamento no decorrer do ciclo (Figura 1), sendo observado que as plantas cultivadas a pleno sol apresentaram menor altura, com diferença mais pronunciada a partir de 28 dias após o transplante. No segundo cultivo, as plantas sob a tela prata $50 \%$ apresentaram altura ligeiramente superior no decorrer do ciclo, todavia, a altura final foi equivalente entre os tratamentos. Também foi observado que as plantas cultivadas com menor sombreamento apresentaram folhas mais eretas.

Quanto ao efeito do manejo do solo sobre a altura das plantas, houve redução na altura final de aproximadamente 4,6 $\mathrm{cm}$ no primeiro cultivo e de $1,0 \mathrm{~cm}$ no segundo cultivo, no manejo com menor revolvimento do solo (Figura 2).

Não houve efeito das telas de sombreamento na umidade do solo no primeiro cultivo, o que pode ser atribuído à realização da amostragem 15 horas após uma chuva de $25 \mathrm{~mm}$, o que uniformizou a umidade (Figura 3). Wolf \& Coltman (1990) também não verificaram diferença de níveis de sombreamento na umidade do solo, o que atribuíram ao excesso de chuvas no período da avaliação. Houve interação entre os manejos 
de solo e as profundidades de avaliação no primeiro e segundo cultivo. O manejo com redução do preparo de solo

apresentou umidade superior em relação ao cultivo com enxada rotativa encanteiradora em todas as profundidades,

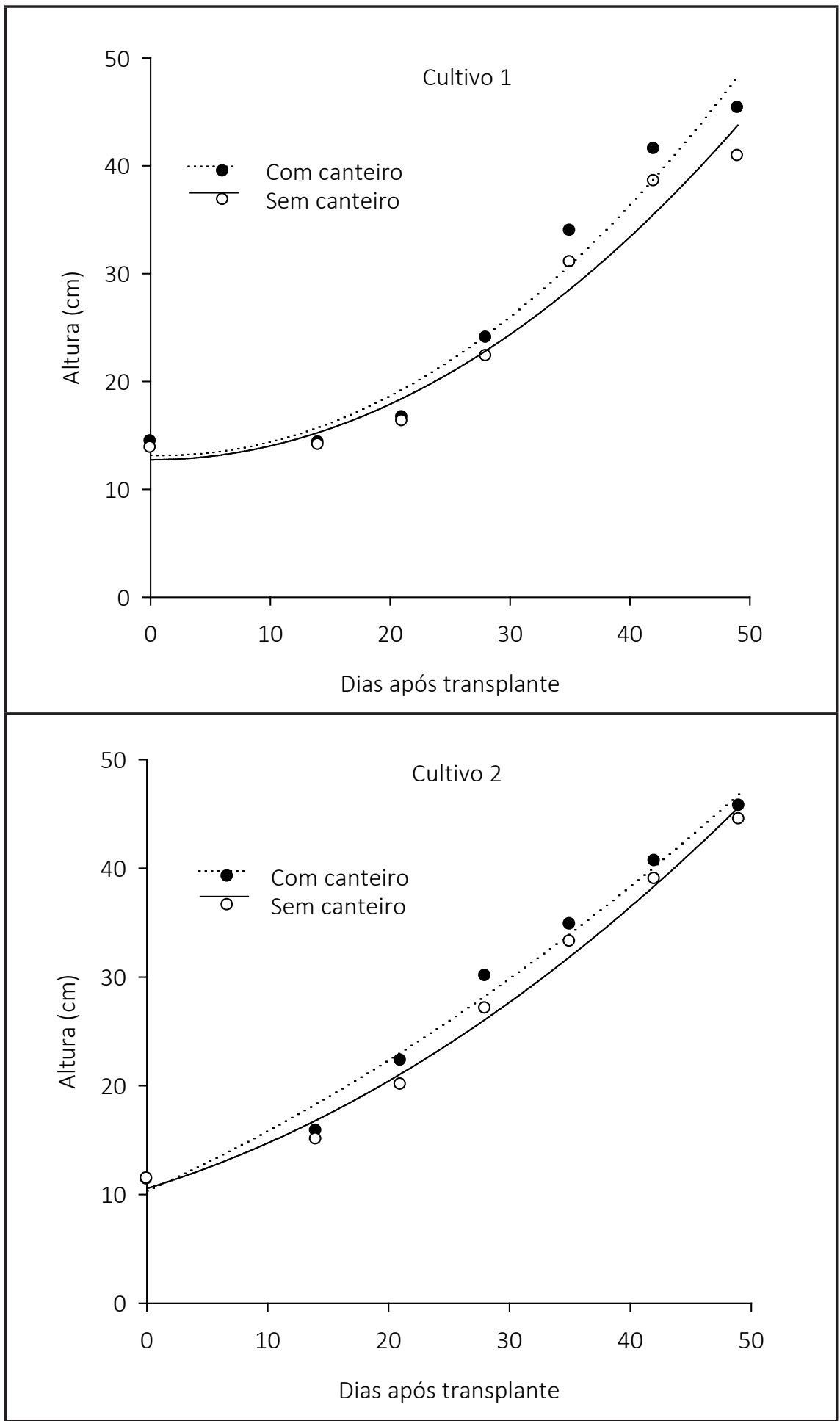

Figura 2. Altura da cebolinha sob diferentes manejos do solo em cultivos sucessivos, no verão (bunching onion height under soil management strategies in summer successive cropping). Presidente Prudente, APTA, 2015.

$\mathrm{Y}_{\mathrm{CC} \text { cultivo } 1}=13,1582-0,0286 \mathrm{x}+0,0152 \mathrm{x}^{2} ; \mathrm{R}^{2}=0,96 ; \mathrm{Y}_{\mathrm{SC} \text { cultivo } 1}=12,7424-0,0006 \mathrm{x}+0,0129 \mathrm{x}^{2}$; $\mathrm{R}^{2}=0,96 ; \mathrm{Y}_{\mathrm{CC} \text { cultivo } 2}=10,3104+0,5033 \mathrm{x}+0,0049 \mathrm{x}^{2} ; \mathrm{R}^{2}=0,99 ; \mathrm{Y}_{\mathrm{SC} \text { cultivo } 2}=10,5560+0,3406 \mathrm{x}$ $+0,0077 x^{2} ; R^{2}=0,99 ; C C=$ com canteiro (presence of seedbed); $S C=$ sem canteiro (absence of seedbed). sendo essa diferença aumentada com a profundidade, o que evidencia maior armazenamento de água neste manejo.

No segundo cultivo da cebolinha, a amostragem foi realizada em situação de baixa umidade do solo, antes da irrigação. De acordo com Reichardt \& Timm (2004) é importante tomar como referência valores de umidade em função do tempo, para compreensão da variabilidade espacial do conteúdo de água no solo, o que realmente ocorreu neste estudo. Nesta situação houve interação entre telas de sombreamento e profundidades de amostragem na umidade do solo. As telas, independentemente da cor (preta ou prata) e da porcentagem de sombreamento (35 ou $50 \%$ ) apresentaram maior umidade do solo em relação ao tratamento a pleno sol. Esse resultado é atribuído ao fato do solo estar mais seco por ocasião dessa avaliação comparado com a avaliação do primeiro cultivo.

É provável que o efeito do sombreamento associado à redução da movimentação de ar proporcionado pelas telas contribuiu de forma mais efetiva na manutenção da umidade do solo. De acordo com estudos realizados por Siqueira et al. (2008), o vento é um dos fatores que apresentam impacto nos valores de perda média diária de água.

Um ponto que também contribui para o efeito positivo da tela em situação de menor umidade do solo é que a cultura da cebolinha não cobre o solo totalmente devido à sua morfologia (folhas cilíndricas e eretas), o que resulta em maior evaporação de água da superfície do solo.

A diferença em relação à manutenção da umidade do solo proporcionada pelas telas foi maior na superfície do solo $(2,5 \mathrm{~cm})$, sendo reduzida com o aumento da profundidade. Não houve diferença estatística entre as telas de sombreamento.

Com base nos resultados obtidos, é possível concluir que o desempenho produtivo da cebolinha em relação ao uso de telas de sombreamento difere com o ambiente de cultivo, mesmo dentro do verão. Em situação de altas temperaturas e menor precipitação pluvial as telas não diferiram do cultivo a 


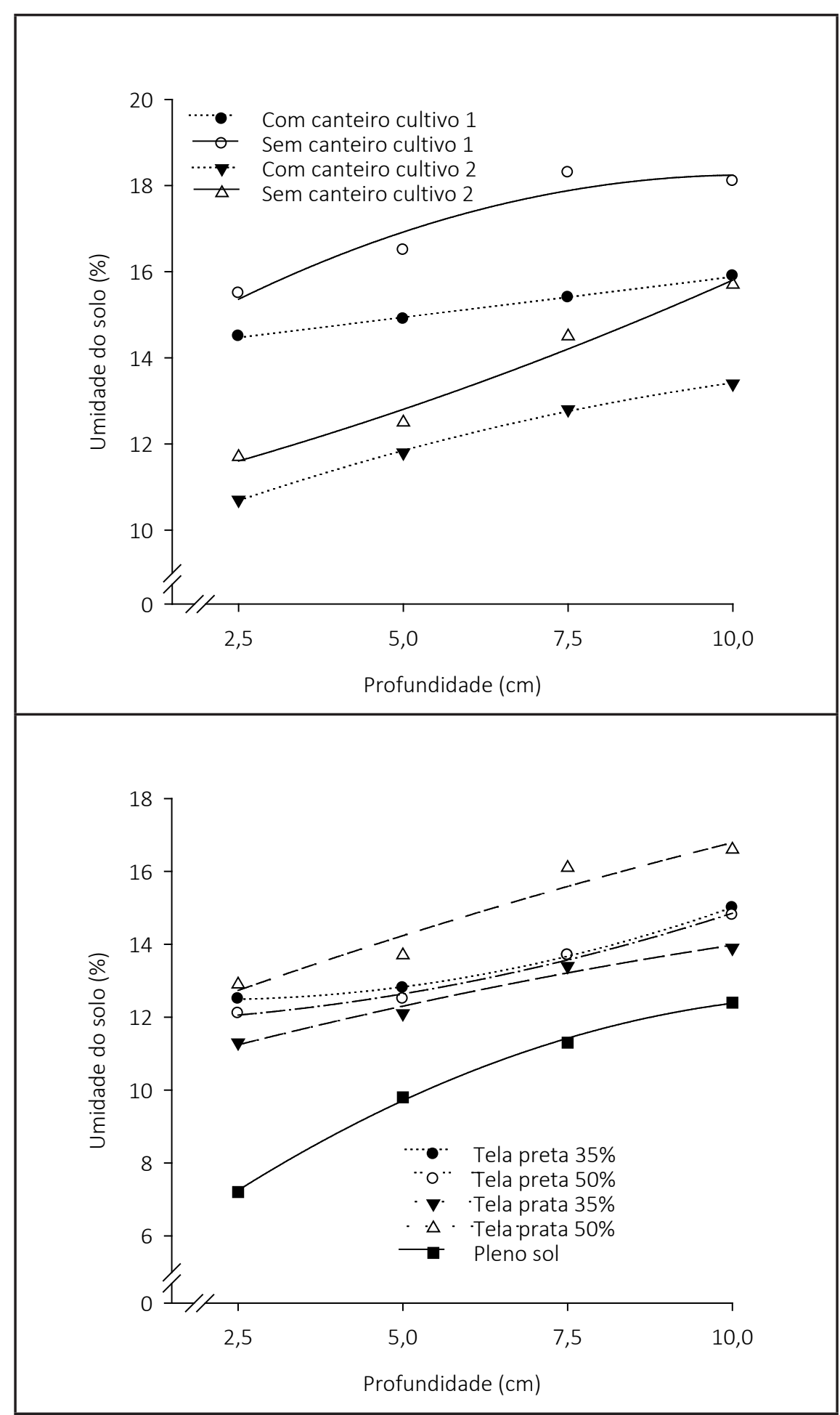

Figura 3. Interação entre profundidades e manejos do solo e entre profundidades do solo e telas de sombreamento na umidade do solo em cultivos sucessivos de cebolinha no verão (interaction between soil depth versus soil management and soil depth versus shading screen on soil humidity in successive bunching onion cropping in the summer). Presidente Prudente, APTA, 2015.

$\mathrm{Y}_{\mathrm{CC} \text { cultivo1 }}=14,0+0,188 \mathrm{x} ; \mathrm{R}^{2}=0,99 ; \mathrm{Y}_{\mathrm{SC} \text { cultivol }}=13,2+0,984 \mathrm{x}-0,048 \mathrm{x}^{2} ; \mathrm{R}^{2}=0,99 ; \mathrm{Y}_{\mathrm{CC} \text { cultivo } 2}=$ $9,275+0,614 \mathrm{x}-0,02 \mathrm{x}^{2} ; \mathrm{R}^{2}=0,99 ; \mathrm{Y}_{\mathrm{SC} \text { cultivo } 2}=10,6+0,36 \mathrm{x}+0,016 \mathrm{x}^{2} ; \mathrm{R}^{2}=0,98 ; \mathrm{CC}=\mathrm{com}$ canteiro (presence of seedbed); $\mathrm{SC}=$ sem canteiro (absence of seedbed); $\mathrm{Y}_{\text {preta } 35 \%}=12,65-$ $0,164 \mathrm{x}+0,04 \mathrm{x}^{2} ; \mathrm{R}^{2}=0,99 ; \mathrm{Y}_{\mathrm{preta} 50 \%}=11,825+0,022 \mathrm{x}+0,028 \mathrm{x}^{2} ; \mathrm{R}^{2}=0,99 ; \mathrm{Y}_{\mathrm{prata} 35 \%}=10,025$ $+0,514 \mathrm{x}-0,012 \mathrm{x}^{2} ; \mathrm{R}^{2}=0,98 ; \mathrm{Y}_{\text {prata } 50 \%}=11,075+0,69 \mathrm{x}-0,012 \mathrm{x}^{2} ; \mathrm{R}^{2}=0,94 ; \mathrm{Y}_{\text {pleno sol }}^{\text {prata } 35 \%}=4,025$ $+1,434 \mathrm{x}-0,06 \mathrm{x}^{2} ; \mathrm{R}^{2}=0,99$. pleno sol, todavia em situação contrária, o cultivo a pleno sol foi mais produtivo. Apesar da redução na produtividade da cebolinha sem a utilização da encanteiradora, este manejo mostrou-se promissor. Houve efeito positivo das telas na manutenção da umidade do solo, especialmente na superfície. O manejo com menor revolvimento do solo resultou em maior retenção de água em todas as profundidades avaliadas.

\section{AGRADECIMENTOS}

Os autores agradecem o apoio financeiro da FAPESP (Fundo de Amparo à Pesquisa do Estado de São Paulo) para a realização deste trabalho.

\section{REFERÊNCIAS}

BEZERRA NETO, F; ROCHA, RCC; NEGREIROS, MZ; ROCHA, RH; QUEIROGA, RCF. 2005. Produtividade de alface em função de condições de sombreamento, temperatura e luminosidade elevadas. Horticultura Brasileira 23: 189-192.

CALIMAN, FRB; SILVA, DJH; FONTES, PCR; STRINGHETA, PC; MOREIRA, GR; CARDOSO, AA. 2005. Avaliação de genótipos de tomateiro cultivados em ambiente protegido e em campo nas condições edafoclimáticas de Viçosa. Horticultura Brasileira 23: 255-259.

CARVALHO FILHO, A; SILVA, RP; CENTURION, JF; CARVALHO, LCC; LOPES, A. 2007. Agregação de um latossolo vermelho submetido a cinco sistemas de preparo do solo em Uberaba-MG. Engenharia Agrícola 27: 317-325.

CEPAGRI. 2015, 30 de abril. Meteorologia Unicamp. Disponível em http://www.cepagri. unicamp.br/outras-informacoes/clima-dosmunicipios-paulistas.html

CHAGAS, JH; RIBEIRO, AS; PINTO, JEBP; BERTOLUCCI, SKV; SANTOS, FM; BOTREL, PP. 2010. Acúmulo de biomassa seca em plantas de Mentha arvensis cultivada sob diferentes malhas e níveis de sombreamento. Horticultura Brasileira 28: 3457-3463.

CIIAGRO. 2015, 30 de abril. Centro Integrado de Informações Agrometeorológicas do IAC. Disponivel em: http://www.ciiagro.sp.gov.br/ ciiagroonline/

COSTA, AG; CHAGAS, JH; BERTOLUCCI, SKV; PINTO, JEBP. 2014. Níveis de sombreamento e tipos de malha no crescimento e produção de óleo essencial de hortelãpimenta. Horticultura Brasileira 32: 194-199.

COSTA, CMF; SEABRA JÚNIOR, S; ARRUDA, GR; SOUZA, SBS. 2011. Desempenho de cultivares de rúcula sob telas de sombreamento e campo aberto. Semina 32: 93-102. 
EMBRAPA - EMPRESA BRASILEIRA DE PESQUISA AGROPECUÁRIA. 1997. Manual de métodos de análise de solo. 2. ed. Rio de Janeiro: Centro Nacional de Pesquisa de Solos. 212p.

FELTRIM, AL; CECÍLIO FILHO, AB; REZENDE, BLA; BARBOSA, JC. 2006. Produção de chicória em função do período de cobertura com tecido de polipropileno. Horticultura Brasileira 24: 249-254.

FILGUEIRA, FAR. 2000. Novo manual de olericultura: agrotecnologia moderna na produção e comercialização de hortaliças. Viçosa: UFV. 402p.

HIRATA, EK. 2014. Respostas fisiológicas da rúcula ao cultivo sob telas fotoconversoras no inverno e no verão. Presidente Prudente: Unoeste. 48p. (Dissertação mestrado).

LARCHER, W. 2006. Ecofisiologia Vegetal. São Carlos: Rima. 532p.

MELO, RAC; MADEIRA, NR; PEIXOTO, JR. 2010. Cultivo de brócolos de inflorescência única no verão em plantio direto. Horticultura Brasileira 28: 23-28.

OLIVEIRA, NG; DE-POLLI, H; ALMEIDA, DL; GUERRA, JGM. 2006. Plantio direto de alface adubada com "cama" de aviário sobre coberturas vivas de grama e amendoim forrageiro. Horticultura Brasileira 24: 112117.

PUIATTI, M; FINGER, FL. 2005. Fatores climáticos. In: FONTES, PCR (ed). Olericultura teoria e prática. Viçosa: UFV, p.17-30.

QUEIROGA, RCF; BEZERRA NETO, F; NEGREIROS, MZ; OLIVEIRA, AP; AZEVEDO, CMSB. 2001. Produção de alface em função de cultivares e tipos de telas de sombreamento nas condições de Mossoró. Horticultura Brasileira 19: 192-196.

QUEIROZ, JPS; COSTA, AJM; NEVES, LG; SEABRA JUNIOR, S; BARELLI, MAA. 2014. Estabilidade fenotípica de alfaces em diferentes épocas e ambientes de cultivo. Revista Ciência Agronômica 45: 276-283.

RAIJ, B; ANDRADE, JC; CANTARELLA, H; QUAGGIO, JA. 2001. Análise química para avaliação da fertilidade de solos tropicais. Campinas: IAC. 284p.

RAIJ, B; CANTARELLA, H; QUAGGIO, JA; FURLANI, AMC (eds). 1997. Recomendações de adubação e calagem para o Estado de São Paulo. 2.ed. rev. e atual. Campinas: IAC. 285p. (Boletim Técnico, 100).
REICHARDT, K; TIMM, LC. 2004. Solo, planta e atmosfera: conceitos, processos e aplicações. Barueri: Manole. 478p.

SILVA, FAS. 2008. Sistema de Assistência Estatística - ASSISTAT versão 7.6 beta (em linha). Departamento de Engenharia Agrícola. Paraíba: Campina Grande.

SIQUEIRA, GM; VIEIRA, SR; CAMARGO, MBP. 2008. Variabilidade espacial do armazenamento e perda média diária de água pelo solo no sistema de semeadura direta em Campinas. Bragantia 67: 213-223.

STEINMETZ, S; DEIBLER, AN; SILVA, JB. 2013. Estimativa da produtividade de arroz irrigado em função da radiação solar global e da temperatura mínima do ar. Ciência Rural 43: 206-211.

TAVELLA, LB; GALVÃO, RO; FERREIRA, RLFF; NETO, SEAN; NEGREIROS, JRS. 2010. Cultivo orgânico de coentro em plantio direto utilizando cobertura viva e morta adubado com composto. Revista Ciência Agronômica 41: 614-618.

WOLF, XY; COLTMAN, RR. 1990. Productivity of eight leafy vegetable crops grown under shade in Hawaii. Journal of the American Society for Horticultural Science 115: 182188. 